\title{
Yersel Lazer Tarama Tekniği Kullanarak Ağzıkara Han'ın 3 Boyutlu Nokta Bulutunun Elde Edilmesi
}

\author{
Engin KANUN*1 ${ }^{*}$, Azim METIN ${ }^{2}$ (b), Murat YAKAR ${ }^{3}$ \\ ${ }^{1}$ Mersin Üniversitesi, Mühendislik Fakültesi, Makine Mühendisliği Bölümü, Mersin, Türkiye \\ ${ }^{2}$ Konya Büyükșehir Belediyesi, KUDEB, Konya, Türkiye \\ 3Mersin Üniversitesi, Mühendislik Fakültesi, Harita Mühendisliği Bölümü, Mersin, Türkiye
}

\author{
Anahtar Kelimeler \\ Ağzıkara Han, \\ Lazer Tarama, \\ Nokta Bulutu, \\ Kültürel Miras.
}

\begin{abstract}
ÖZ
Türkiye, dünyadaki konumu sebebiyle birçok medeniyete ev sahipliği yapmıştır. Bu eserlerin korunması ve gelecek nesillere aktarılması kültürel mirasa sahip çıkmak açısından oldukça büyük önem arz etmektedir. Bu eserler zaman içerisinde zemin ve hava koşulları, malzeme bozunumları, doğal afetler, yangın, savaş ve kötü kullanım gibi sebeplerden ötürü büyük hasara uğrayabilmektedir. Bu gibi durumlarda eserlerin korunması ve gelecek nesillere aktarılabilmesi için belgelenmesi gerekmektedir. Kültürel mirasın gelecek nesillere aktarılması kapsamında var olan eserlerin ve yapıların belgelenmesi işlemlerinde teknolojik aletler ve yöntemler kullanılmaktadır. Bu çalıșma kapsamında Türkiye'de yer alan ve Selçuklu döneminde inşa edilmiş tarihi bir kervansaray olan Ağzıkara Han'ın 3 boyutlu (3B) nokta verilerinin oluşturulması maksadıyla yersel lazer tarama yöntemi kullanılmıștır. Lazer tarama işlemi Faro X 330 aletiyle yapılmış ve nokta bulutu verisi üretilmiştir. Lazer tarama verilerinin birleştirme hataları da hesaplanmış ve kabul edilebilir mertebede olduğu sonuçlarda gösterilmiștir. Ortalama birleştirme hatası $5.9 \mathrm{~mm}$ olarak hesaplanmış ve verilerin \%43.3'ü 4 mm'nin altında hata değerine sahiptir.
\end{abstract}

\section{Obtaining 3D Point Cloud of Agzikara Khan Using Terrestrial Laser Scanning Method}

\section{Keywords}

Agzikara Khan,

Laser Scanning,

Point Cloud,

Cultural Heritage.

\begin{abstract}
Turkey has hosted many civilizations due to its location on the worldPreserving these assets and transferring them to future generations is of great importance in terms of protecting the cultural heritage. These artifacts can suffer great damage over time due to ground and weather conditions, material degradation, natural disasters, fire, war and misuse. In such cases, it is necessary to document the artifacts in order to protect them and transfer them to future generations. Technological tools and methods are used in the documentation of existing artifacts and structures within the scope of transferring cultural heritage to future generations. Within the scope of this study, terrestrial laser scanning method was used in order to create 3D point data of Agzikara Khan, which is a historical caravanserai built in the Seljuk period in Turkey. Laser scanning was performed with the Faro X 330 instrument and point cloud data was generated. Combination errors of laser scan data were also calculated and shown in the results to be acceptable. The mean overlap error was calculated as $5.9 \mathrm{~mm}$ and $43.3 \%$ of the data had an error value of less than $4 \mathrm{~mm}$.
\end{abstract}




\section{GİRiş}

Türkiye'nin Aksaray ilinin Ağzıkarahan Köyü'nde yer alan ve Selçuklu döneminde inşa edilmiş tarihi bir kervansaray olma özelliği taşıyan Ağzıkara Han, UNESCO Dünya Miras Listesi'ne aday olarak da gösterilmiştir (T.C. Kültür ve Turizm Bakanlığı, t.y.). Ağzıkara Han, 38 $26^{\prime}$ 42.87" kuzey, 34 8' 25.45" doğu koordinatlarına sahiptir. Han'ın konumu Şekil 1'de görülmektedir:

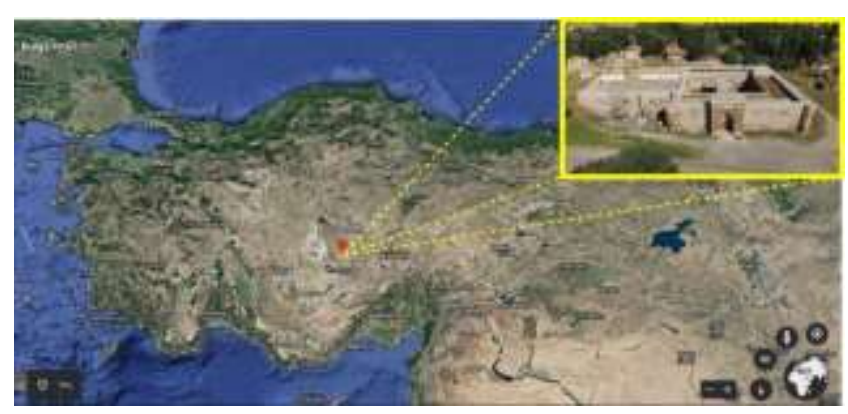

Şekil 1. Ağzıkara Han'ın konumu

\subsection{Ağzıkara Han'ın Tarihçesi ve Literatür Araştırması}

Han'a ait kitabelerden edinilen bilgilere göre kapalı bölüm (hol) ve açık avlusu olmak üzere iki aşamada inşa edilmiştir. Hol bölümü 1231'de Anadolu Selçuklu Sultanı I. Alâeddin Keykubad zamanında, açık avlusu ise II. Glyâseddin Keyhusrev'in ilk saltanat yıllarında 1237'de tamamlanmıştır. Avlunun yan eksenine alınmış taçkapısı, köșe kuleleri ve ağır payandası ile kale görünümüne en çok sahip olan Anadolu Selçuklu kervansarayıdır. Binanın açık avlu bölümü tamamen kesme taştan inşa edilmiştir ve dört eyvan şemasını yaşatmaktadır. Girişin yanındaki bölümler sundurma şeklinde, karşıdaki bölümler ise eyvan çevresinde kapalı mekanlar halinde konumlanmıştır. Şekil 2'de Ağzıkara Han'ın genel görünümü sunulmaktadır. Avlunun orta kısmında ise iki tarafından merdivenlerle çıkılan sultan hanlarının köşk mescidi bulunmaktadır. Dıştaki gibi geometrik motiflerle süslenen iç kısımdaki taçkapıdan ise kapalı bölüme girilmektedir (Altun 1988).

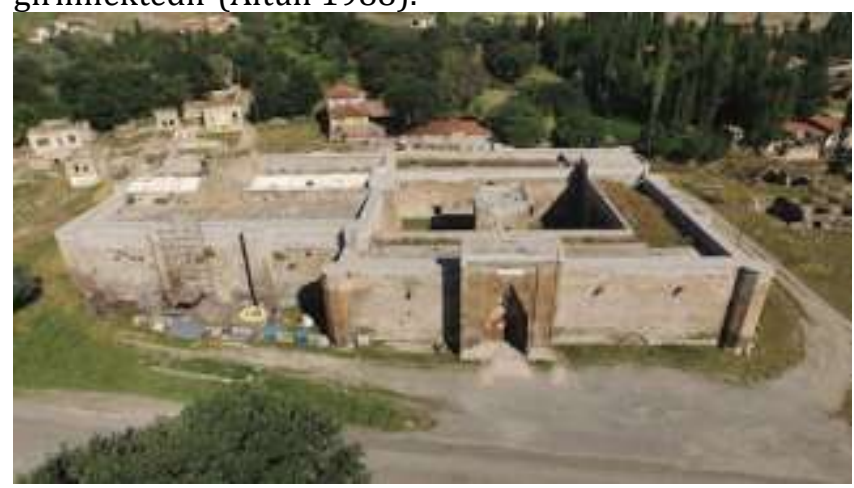

Şekil 2. Ağzıkara Han genel görünümü (URL-1)

Ağzıkara Han'ın açık avlu portalinin rölöve çalışmaları sırasında açığa çıkan bilgilere göre yapının zaman içerisinde hangi sebeplerle hasara uğradığına dair bulgular vardır. En şiddetli bozulmalar portalin alt kısımlarında malzeme kaybı olarak gözlemlenmiştir ve bu da anıtta yerden yükselen nem probleminin varlığını işaret etmektedir. Portalin üst kısımlarında ise oyuklu malzeme kaybı olduğu izlenmiştir. Yapılan çalışmalar neticesinde bu durumun da çatı kısmındaki nem ve drenaj probleminden kaynaklandığı görülmüștür. Yapı onarım geçirmesine rağmen bazı sorunların devam ettiği sonucuna varılmıștır (Caner 1999). Ağzıkara Han ile ilgili yapılan bir doktora çalışmasında iç avlu portalindeki malzeme kayıpları ve yapıda zamanla meydana gelen bozulmalar gösterilmiștir (Tavukçuoğlu 2001).

Ağzıkara Han, Aksaray-Nevşehir karayolunun eski güzergahı üzerinde yol kenarında bulunmaktaydı. Eskiden bu yol köyün içinden geçerken 2004 yılında yapılan yeni yolun sonucunda tarihi han anayoldan 2 kilometre dışarıda kalmıştır. Bazı tarihi kaynaklarda Hoca Mesud Ribatı adıyla da bilinmekte olan bu kervansarayın açık ve kapalı kısımları yazlık ve kışlık olarak kullanılmıștır. 13. Yüzyılda inşa edilen bu kervansaray 19. Yüzyıldan itibaren kullanılmaz hale gelmiştir. Vakıflar Genel Müdürlüğü tarafından 19701975 yıllarında onarılmıştır. Bir dönem kiralanarak hem turistik amaçla ziyarete açılmış hem de turistik eşyaların satıldığı bir mekan olarak kullanılmıştır (Yetiş \& Kaygısız 2017).

2017 yılında yayınlanan bir diğer araştırma makalesinde Ağzıkara Han ve beraberindeki Anadolu Selçuklu yapılarının mimarisindeki geometrik süsleme ve motifler incelenmiş ve kullanılan kompozisyonlar detaylı bir şekilde irdelenmiştir (Bulut 2017). Şekil 3'te Ağzıkara Han'ın kapalı kısım taçkapısında bulunan süslemeler görülmektedir:

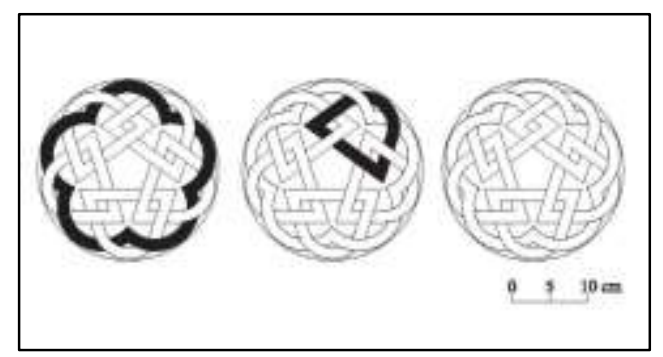

Şekil 3. Ağzıkara Han kapalı kısım taçkapısındaki süslemeler (Bulut 2017)

Ağzıkara Han literatürde ilk olarak 1908'de H. Rott tarafından tanıtılmıștır. Bunun akabinde 1918'de Halil Edhem tarafından yayınlanan bir çalışmada, kervansarayın inşasına 1231 'de Alâeddin Keykûbat zamanında başlandığı ve oğlu Keyhusrev döneminde ise tamamlandığı belirtilmiştir. 1942 yılında K. Bittel tarafından yayınlanan bir çalışmada Sivas-KayseriKonya yolu üzerindeki kervansarayların önemi aktarılmış ve Ağzıkara Han'ın dört adet fotoğrafı sunulmuştur. Han, Şelçuklu kervansaraylarının en iyi korunan örneklerinden birisi olmuştur. Portal çerçevesi oyma kabartmalarla gayet güzel bir şekilde süslenmiştir. Kapı üzerinde bulunan yarım kubbesi ise sarkıtlıdır. Sarkıtı çevreleyen iç içe geçmiş motiflerle süslenmiş düz yüzey sivri bir kemerin içine alınmıştır. Kemerin üzerinde 2 satırlık mermer bir kitabe bulunmaktadır. Kitabenin iki tarafında ve aşağı kısmında ise on tane nakışlı gül vardır. Karşılıklı iki kapı bulunduran niş arasından ve önü açık tonozlu bir kısımdan hanın açık bölümüne girilir. Avlunun orta kısmında, portalin karşısında dört ayağa basan dört kemerin üzerine, kare tabanlı bir mescit inşa edilmiştir (Özgüç \& Akok 1956). Şekil 4'te Ağzıkara Han'a ait bir restütisyon çalışması görülmektedir: 


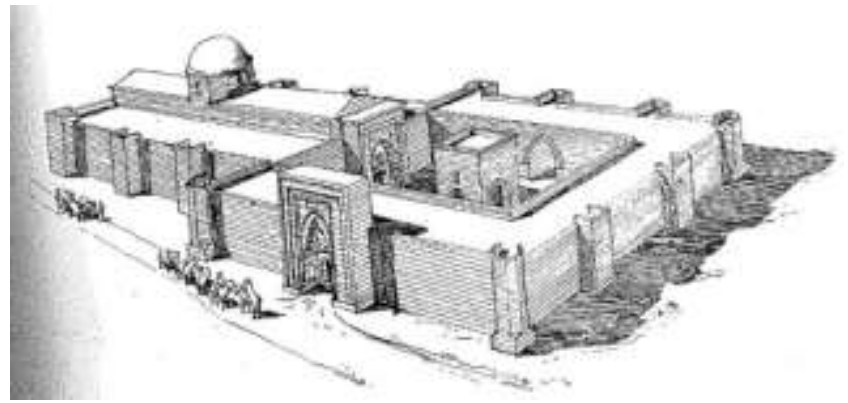

Şekil 4. Ağzıkara Han restütisyon çalışması (Özgüç \& Akok 1956)

Bir diğer makalede, Ağzıkara Han gibi 13. Yüzyılda Anadolu'da inşa edilen birçok yapının taçkapılarında kullanılan madalyon ve kabaralar detaylı ve kapsamlı bir biçimde incelenmiş, benzerlikleri ve farklılıkları ele alınmıştır (Yaman \& Ertunç 2019).

Ağzıkara Han, Anadolu Selçuklu yapıları içinde az bozulmuş ve taşçı işaretleri açısından en zengini olduğundan, bir çalışmada ayrıntılı belgeleme için örnek olarak seçilmiştir. Yapılan ayrıntılı incelemeler sonrasında 79 adet taşçı işareti saptanmıştır. Dürbün ve özel aydınlatma elemanları yardımıyla yapılan çalışmada, hanın kapalı kısmında 55, açık kısmında 47 işaret tespit edilmiştir. Her iki bölümde de ortak görülen işaret sayısı ise 23 'tür. İşaretlerin yerleri yapı planları üzerinde gösterilmiş ve bölümlere ayrılarak belgelenmiştir (Binan \& Binan 2009).

Bir başka çalışmada ise, yapıda ciddi rutubet problemleri olduğu tespitinden yola çıkılarak Ağzıkara Han'ın kızılötesi termografisi yöntemi kullanılarak araştırması yapılmıştır (Tavukçuoğlu vd. 2005).

2019 yılında yayınlanan bir çalışmada, Ağzıkara Han'ın tarihçesinden ve konumundan bahsedilmiş, turizm verileri kullanılarak "kültürel iz koridoru" adı verilen rotalar oluşturulmuştur. Kültürel mirasın değer kazanmasına yönelik yeni yönetimsel önlemler geliştirilmesini mümkün kılan bu çalışmada, Ağzıkara Han gibi varlıkların turizm açısından çekim alanına dönüştürülmesine yönelik strateji ve öneriler geliştirilmiştir (Yenil \& Akyazı 2019).

Bir başka çalışmada ise, 13. yüzyıla ait Selçuk Dönemi kervansaraylarından Ağzıkarahan tüfleri, yapının yakınında bulunan antik taş ocaklarının ortaya çıkarılması için örnek olay olarak incelenmiştir. Duvarları, içte ve dışta kesme tüf bloklarla karşı karşıya kalan moloz taş dolgu ile örülmüştür. Yapının özgün ve yenilenen tüf blokları, yakındaki tüf ocaklarıyla ilişkilendirilerek incelenmiştir. Yapının güneydoğusunda yer alan Saratlı köyünde ve Saratlı'nın biraz ilerisindeki Mamasın köyünde bazı eski ve yeni tüf ocakları araştırılmıştır. Bunlardan yapının orijinal ve yenilenmiş tüflerinin muhtemel kaynakları olduğu düşünülen üç tüf ocağı daha detaylı olarak incelenmiştir (Caner-Saltık vd. 2007).

\subsection{Yersel Lazer Tarama (YLT) Tekniği}

Yersel lazer tarama (YLT) teknolojisi birçok meslek dalında yaygın olarak kullanılmaktadır. Mühendisler, mimarlar, arkeologlar, biyologlar, tarihçiler, doktorlar vb. birçok meslek lazer tarama teknolojisi kullanarak ölçümler yapmakta ve modeller üretmektedir (Yllmaz vd., 2012). Yersel lazer tarama tekniğinin kullanıldığı en önemli alanlardan bir tanesi de kültürel mirasın dökümantasyonu çalışmalarıdır. Geçmișten günümüze, nesilden nesile aktarılmış bir çok tarihi eser ve yapı bulunmaktadır ve bu yapıların gelecek nesillere aktarılması büyük önem arz etmektedir. YLT teknolojisi kullanılarak tarihi yapıların belgelenmesi işlemine dair çalışmalara literatürde de sıklıkla rastlanmaktadır. Bir anit mezarın 3B olarak modellenmesi (Erene \& Yakar, 2012; Yakar vd., 2005; 2009; Alptekin vd. 2019a; 2019b), tarihi bir kalenin nokta bulutu verisinin elde edilmesi (Ulvi \& Yakar 2014) gibi örnekler YLT teknolojisi ile tarihi yapıların ve kültürel mirasın 3B olarak başarıyla belgelenebildiğini göstermektedir.

Yersel lazer tarayıcılarda kullanılan ölçüm metodunun temel çalışma mantığı, lazer ışığı sinyalinin ölçüm cihazı ile ölçülen cisim arasındaki gidiş-dönüş süresinin ölçülmesi ilkesine dayanmaktadır (Özdoğan \& Deliormanlı 2018).

Yatay ve düșey eksende lazer ışını gönderen bir mekanizmaya sahip olan yersel lazer tarayıcıların elektronik ünitesinden çıkan ışın, cihazın gövde kısmında bulunan optik üniteye çarpar ve bu yüzeyden yansıyarak cihazdan çıkar. Cihazdan çıkan ışın yatay eksenle bir açı yapar. Düşey eksen etrafında çok küçük açılarla dönerek tarama işlemine devam eden cihaz veri almaya devam eder. Bu süreç tarama işlemi tamamlanana kadar devam eder (Vozikis vd. 2004; Özdoğan 2015). Şekil 5'te YLT çalışma prensibine ait şematik bir çizim sunulmuştur:

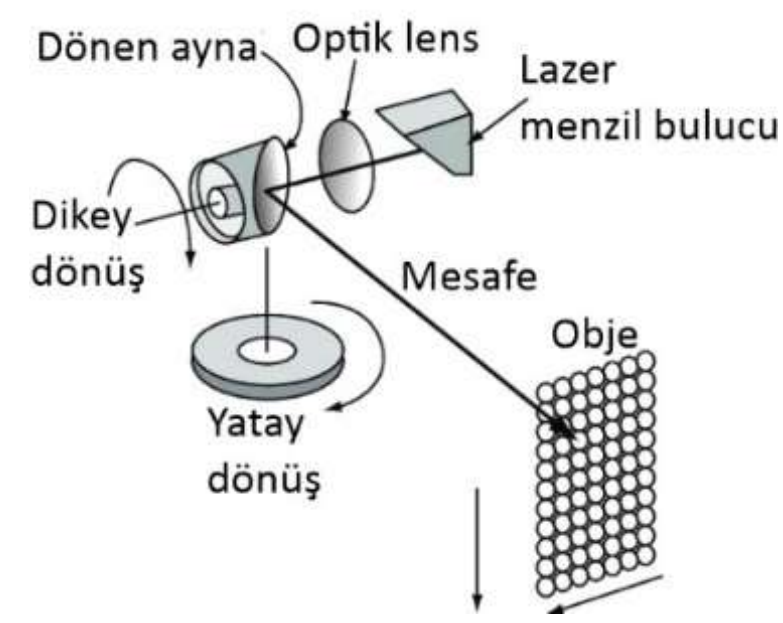

Şekil 5. YLT çalışma prensibi şeması (Petrie \& Toth 2009)

Her tarama sonunda veriler nokta bulutu adı verilen noktalar olarak kullanıcıya sunulur ve bu nokta bulutundaki her lazer noktası kutupsal koordinatlarla (r, $\varphi, \theta)$ tarayıcıya kaydedilir. Bu kutupsal koordinatlarla ifade edilen noktaların kartezyen koordinatları $(\mathrm{x}, \mathrm{y}, \mathrm{z})$ tarayıcı yazılımı tarafından hesaplanır ve kullanıcıya kartezyen koordinatlar olarak sunulur (Yakar vd., 2010; Yılmaz \& Yakar, 2008; Özdoğan \& Deliormanlı 2018). Lazer tarayıcı tarafından ham olarak alınan kutupsal koordinatlar, kartezyen koordinatlara dönüştürülürken kullanılan matris Denklem 1'de verilmiştir:

$$
x_{i}=\left[\begin{array}{l}
x_{j} \\
y_{j} \\
z_{j}
\end{array}\right]_{3 x 1}=\left[\begin{array}{c}
r_{j} \cos \varphi_{j} \cos \theta_{j} \\
r_{j} \sin \varphi_{j} \cos \theta_{j} \\
r_{j} \sin \theta_{j}
\end{array}\right]_{3 x 1}
$$




\section{YÖNTEM}

Bu çalışmanın yapılması, arazi ve ofis çalışmaları olmak üzere 2 safhadan oluşmaktadır. Çalışma alanının kontrol edilmesi, tarama işlemleri için hazırlanması ve yersel lazer tarama cihazıyla tarama işleminin yapılması adımları arazi çalışması safhasını oluşturmaktadır. Ofis çalışmaları safhasında ise yersel lazer tarayıcıdan alınan verilerin bilgisayar ortamına aktarılması ve yorumlanıp işlenmesi adımları gerçekleștirilmiştir.

\subsection{Arazi Çalışması}

Çalışmanın bu safhasında ilk olarak çalışma alanı olan Ağzıkara Han ve çevresinde kontroller yapılarak taramaların yapılacağı muhtemel bölgeler şematize edilmiştir. Tarama işlemleri Faro Focus X 330 lazer tarayıcı cihaz ile gerçekleștirilmiştir.

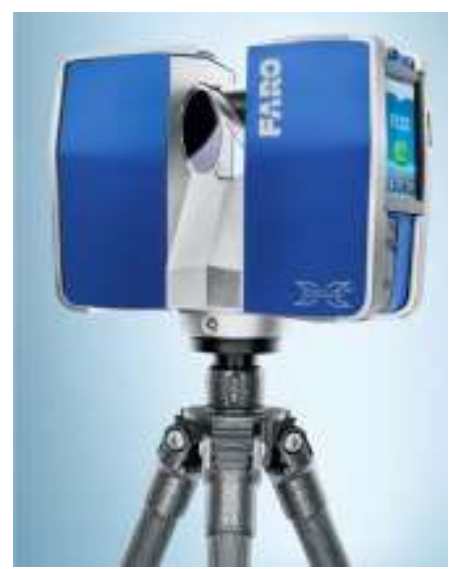

Şekil 6. Faro Focus X 330 lazer tarayıcı

Kullanılan lazer tarayıcının teknik özellikleri Tablo 1'de görülmektedir:

Tablo 1. Faro Focus 3D X 330 lazer tarayıcı özellikleri (Faro 2015)

\begin{tabular}{cc}
\hline Öznitelik & Değer \\
\hline Netlik aralığı & 614 metrede saniyede $122-$ \\
& 488 bin nokta; 307 metrede \\
saniyede 976 bin nokta \\
Mesafe & Kapalı veya açık alan ve \\
& $090^{\prime}$ a kadar yansıtıcı \\
& yüzeyde normal geliş açısında \\
& $0.6 \mathrm{~m}-330 \mathrm{~m}$ arası \\
Ölçümleme hızı & $122.000 / 244.000 / 488.000$ \\
& $/ 976.000$ nokta/saniye \\
Mesafe hatası & $\pm 2 \mathrm{~mm}(0.6 \mathrm{~m}-330 \mathrm{~m}$ arası $)$ \\
Çözünürlük & Renkli 70 megapiksele kadar \\
Görüş alanı (dikey/yatay) & $300^{\circ} / 360^{\circ}$ \\
\hline
\end{tabular}

Aksaray'a 17 km uzaklıkta olan Ağzıkara Han'ın çevresi kabaca 240 metre, oturumu ise 2650 metrekare civarındadır. Taramalara öncelikle dış kısımdan bașlanarak yapının çevresi belgelenmiș, devamında ise iç taramalar yapılmıștır.
Lazer tarama ișlemleri 26 oturum bina dıșı ve 109 oturum bina içi olmak üzere toplam 135 oturumdan oluşmaktadır. Şekil 7 ve Şekil 8'de arazi çalışması kapsamında yapılan yersel lazer tarama işlemlerine ait ait görüntüler sunulmuştur.

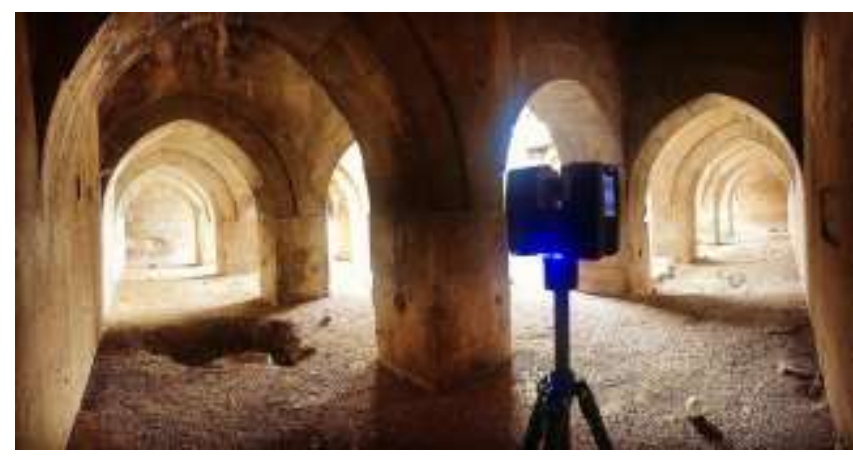

Şekil 7. Yersel lazer tarama işlemi (iç mekan)

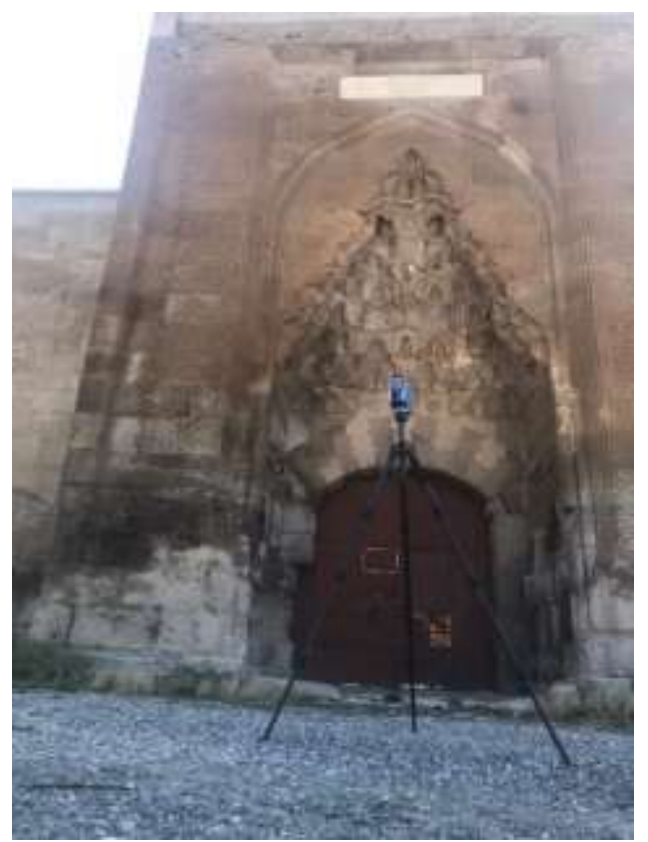

Şekil 8. Yersel lazer tarama işlemi (dış mekan)

\subsection{Ofis Çalışması}

Arazi çalışması kapsamındaki taramaların tamamlanmasının ardından ofis çalışmaları safhasına geçilmiştir. Öncelikle sahadan elde edilen veriler bilgisayar ortamına aktarılmıștır. Tarama sonucu elde edilen nokta dosyası toplam 29 GB yer kaplamıştır. Verilerin işlenmesi Faro SCENE yazılımında yapılmıștır. 4 gün süren arazi çalışmasının ardından başlatılan ofis çalışması bir haftada tamamlanmıştır.

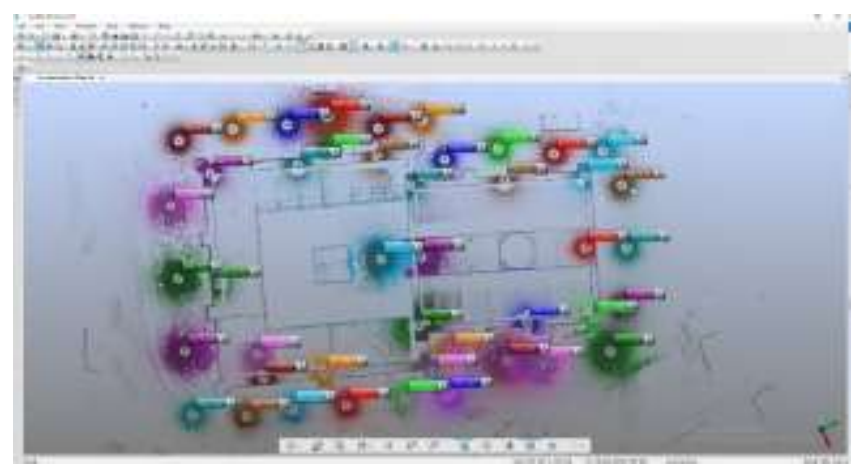

Şekil 9. Tarama yapılan istasyonlardan bazıları 
Şekil 9'da lazer tarama ișlemlerinin yapıldığı istasyonlar görülmektedir. Nokta bulutu verisini elde etmek için öncelikle taramalar yazılımda cloud-to-cloud yöntemiyle işlenmiştir. Taramaları renklendirme seçeneği aktif olarak seçilmiştir. Kenar yapı filtresi dışında herhangi bir filtreleme uygulanmamıştır. İlk aşamada otomatik birleştirme uygulanmış, daha sonraki süreçte ise gerek görülen taramalarda manuel düzeltmeler yapılmıştır. Tüm bu işlemler sonucunda elde edilen nokta bulutundaki nokta sayısı 2,998,510,412 adettir. Taramaların yerlerinin konumlanmasının ardından kervansaray çevresindeki ve içerisindeki yerleri Şekil 10'daki gibidir:

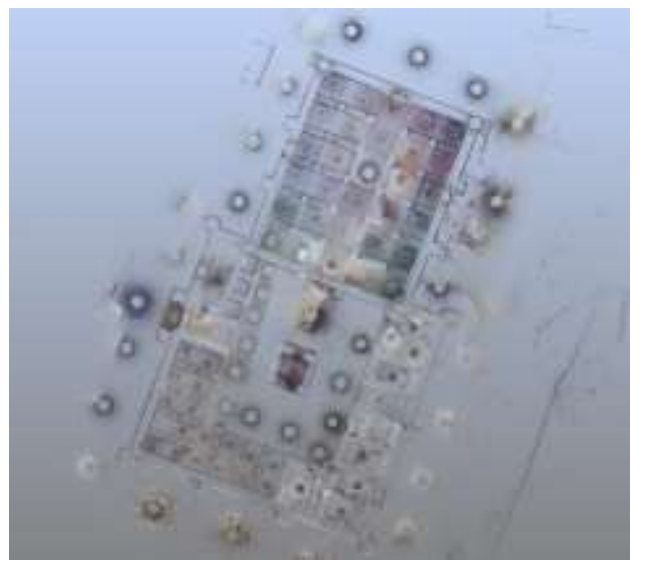

Şekil 10. Konumlama işleminden sonra istasyonların yerleri

Lazer tarama verilerinin birleştirme işlemine ait hata değerleri Tablo 2'deki gibidir. Burada taramaların ortalama kaç milimetre hata ile birleştiği ve yüzde kaç mertebede örtüştüğü görülmektedir.

Tablo 2. Birleșme hataları ve örtüșme yüzdeleri

\begin{tabular}{|c|c|c|c|c|c|}
\hline $\begin{array}{c}\text { Küme/ } \\
\text { Tarama } \\
1\end{array}$ & $\begin{array}{c}\text { Küme/ } \\
\text { Tarama } \\
2\end{array}$ & $\begin{array}{c}\text { Ortalama } \\
{[\mathrm{mm}]}\end{array}$ & $\begin{array}{l}<4 \\
\mathrm{~mm} \\
{[\%]}\end{array}$ & $\begin{array}{c}\text { Örtüşme } \\
{[\%]}\end{array}$ & $\begin{array}{r}\text { Kul. } \\
\text { Nokt. }\end{array}$ \\
\hline Rek3210 & Rek3209 & 2.25 & 75.9 & 88.9 & 41933 \\
\hline Rek3201 & Rek3200 & 2.229 & 66.8 & 85. & 41994 \\
\hline Rek3204 & Rek3203 & 2.215 & 70.5 & 75.7 & 36364 \\
\hline Rek3312 & Rek3192 & 2.192 & 72.5 & 31.4 & 7761 \\
\hline Rek3203 & Rek3202 & 2.162 & 70.0 & 85.9 & 42639 \\
\hline Rek3207 & Rek3206 & 1.707 & 73.8 & 92.6 & 44686 \\
\hline \multicolumn{3}{|c|}{ Ortalama $=5.92 \mathrm{~mm}$} & \multicolumn{3}{|c|}{$<4 \mathrm{~mm}: \% 43.3$} \\
\hline
\end{tabular}

\section{BULGULAR}

Yersel lazer tarayıcı sayesinde Türkiye'nin Aksaray ilinde bulunan Anadolu Selçuklu dönemine ait tarihi bir kervansaray olan Ağzıkara Han'ın birebir ölçülerinde 3B nokta bulutu verisi elde edilmiștir. Kervansaraya ait renkli nokta bulutu verisi Şekil 11'de sunulmuştur:

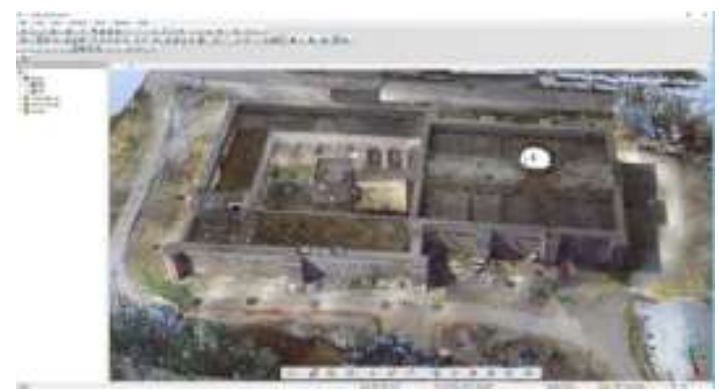

Şekil 11. Ağzıkara Han 3B nokta bulutu
Nokta bulutu verisinin olușturulması neticesinde artık yapının geometrik şekli ve ölçüleri belgelenmiştir. $\mathrm{Bu}$ veri, üzerinde farklı işlemler ve ölçümler yapılarak tarihi han ile ilgili ileride yapılabilecek olası projelerde kullanılabilecektir. Ağzıkara Han'ın 3B nokta bulutu verisinden alınmış bir orta kesit Şekil 12'de görülmektedir. Burada hana ait kapalı ve açık bölümler detaylı bir şekilde görülmektedir. Hana ait veriler üzerinde uzunluk, alan ve hacim gibi ölçümler yaplabilmektedir.

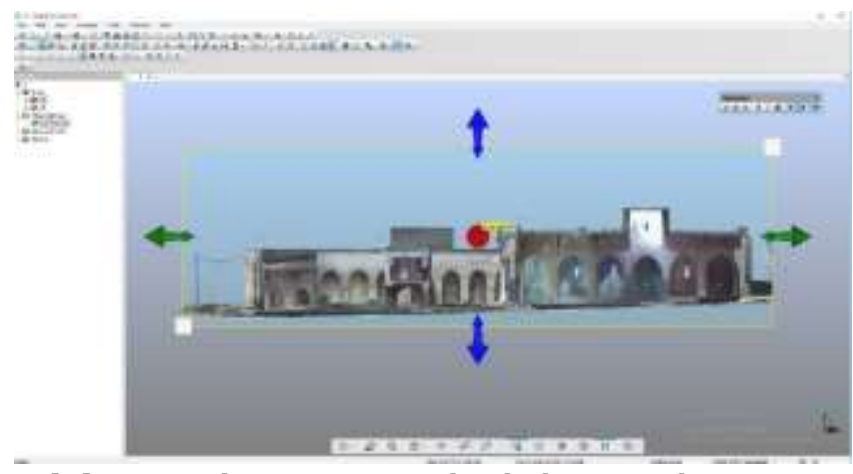

Şekil 12. Ağzıkara Han 3B nokta bulutu orta kesiti

\section{SONUÇ VE TARTIŞMA}

Bu çalışma kapsamında Ağzıkara Han'a ait 3B nokta bulutu verisi yersel lazer tarama teknolojisi kullanılarak yapıya herhangi bir zarar verilmeden elde edilmiştir. Elde edilen nokta bulutu verisi yapı ile birebir aynı ölçektedir. Ortalama birleştirme hatası $5.9 \mathrm{~mm}$ olarak hesaplanmıș ve verilerin \%43.3'ü 4 mm'nin altında hata değerine sahiptir. Daha yüksek bilgisayar gücü ile verilerin işlenmesi süreci hem hızlanacak hem de daha düşük hatada sonuçlar verecektir. Sonuçları etkileyen bir diğer faktör ise güneş ışığının yapı yüzeylerindeki yansımalarıdır. Taramaları güneşin yapı çevresindeki konumuna göre ayarlamak da elde edilen hata değerini düşürecektir.

Kültürel miras açısından oldukça büyük öneme sahip ve bir Anadolu Selçuklu dönemi eseri olan bu kervansarayın belgelenmesi işlemi tamamlanmıştır. Literatürde Ağzıkara Han ile ilgili erişilebilen tüm çalışmalara değinilmiștir. Daha önceki çalışmalarda söz konusu hanın tarihinden bahsedilmiş, tarihsel bakış açısıyla önemi vurgulanmıştır. Özgüç ve Akok'un 1956 yılında yaptığı çalışmada dönemin teknolojik imkanları kullanılarak hana ait restütisyon çalışması yapılmıştır. $\mathrm{Bu}$ çalışma kapsamında ise güncel teknolojik yöntemlerden biri olan yersel lazer tarama yöntemi ile kervansarayın iç ve dış kısımlarının 3B modellemesi yapılmıştır. Elde edilen 3B model sayesinde literatürde var olan daha önceki çalışma bulguları kıyaslanabilecek ve yapı üzerinde zaman içerisindeki değişim gözlemlenebilecektir. Örneğin bir çalışmada Ağzıkara Han'ın kapalı kısmında bulunan taç kapısındaki süslemeler üzerine çalışılmış ve bulgular sunulmuştur (Bulut 2017). Söz konusu çalışmada elde edilen bulgular ile kervansarayın günümüzdeki durumunun kıyaslanması bu çalışmada elde edilen 3B model ile yapılabilecektir.

$\mathrm{Bu}$ çalışmanın geliştirilmesi için gelecekte insansız hava aracı (İHA) ile havadan fotoğraflar çekilerek yapının 
çatı kısmının daha detaylı ve doğru şekilde belgelenmesi sağlanabilecektir.

Elde edilen veriler sayesinde tarihi yapı belgelenmiş ve eserin gelecek nesillere aktarılması yolunda önemli bir adım atılmıştır. İleride yapıda oluşabilecek olan hasarlara karşı şimdiden çalışmalar yapmak önemlidir. Bu çalışmada üretilen nokta bulutu verisi; bakım, onarım, restorasyon ve rölöve gibi çalışmalarda rahatlıkla kullanılabilecek şekildedir.

$\mathrm{Bu}$ çalışmanın bir diğer sonucu olarak söz konusu tarihi kervansarayın turizme daha fazla dahil edilmesi ve bulunduğu bölgeye katkı sağlaması öngörülmektedir. Bölgenin turizm potansiyelini arttırmak için yetkili kuruluşlar bu verileri kullanabilecektir.

$\mathrm{Bu}$ çalışmada elde edilen verilerin aynı zamanda tarihçiler ve arkeologlar için de önemli ve kullanılabilir nitelikte olduğu düşünülmektedir.

\section{Bilgilendirme/Teşekkür}

Makalenin hazırlanması sürecinde desteklerini eksik etmeyen Mersin Üniversitesi Harita Mühendisliği Bölümü personeli ve Konya Vakıflar Bölge Müdürü Nurullah OSMANLI'ya teşekkürlerimizi borç biliriz.

\section{Yazarların Katkısı}

Azim Metin: Saha çalışması ve iş akışı planlaması, veri toplama ve lazer tarama işlemleri, fikir, konsept ve yazma.

Engin Kanun: Ofis çalışması ve planlaması, veri işleme, lazer tarama işlemleri, literatür taraması ve yazma.

Murat Yakar: Veri analizi ve kontrol.

\section{Çıkar Çatışması Beyanı}

Yazarlar arasında herhangi bir çıkar çatışması bulunmamaktadır.

\section{Araştırma ve Yayın Etiği Beyanı}

Yapılan çalışmada araştırma ve yayın etiğine uyulmuştur.

\section{KAYNAKÇA}

Ağzıkara Han (2021). Erişim adresi: http://www.turkishhan.org/agzikara.htm

Alptekin A, Çelik M Ö \& Yakar M (2019a). Anıtmezarın yersel lazer tarayıcı kullanarak 3B modellenmesi. Türkiye LIDAR Dergisi, 1(1), 1-4.

Alptekin A, Çelik M Ö, Doğan Y \& Yakar M (2019b). Mapping of a rockfall site with an unmanned aerial vehicle. Mersin Photogrammetry Journal, 1(1), 1216.

Altun A (1988). Ağzıkara Han. TDV İslâm Ansiklopedisi 1, 482-483. İstanbul

Binan C \& Binan D U (2009). Ağzıkara Han Örneğinde Anadolu Selçuklu Dönemi Taşçı İşaretlerinin Belgelenmesi Üzerine Sistematik Bir Yaklaşım. Adalya, 12, 79-108.
Bulut M (2017). Geometrik sistemin çözümlenmesi Selçuklu örnekleri üzerine birkaç girişim. Sanat Tarihi Dergisi, 26(1), 27-44.

Caner-Saltık E N (1999). Taş ve seramik eserlerin özelliklerinin ve bozulmalarının koruma amacıyla incelenmesi. I. Ulusal Taşınabilir Kültür Varlıkları Konservasyonu ve Restorasyonu Kolokyumu, Ankara, Türkiye, 107-117.

Caner Saltık E N, Akoğlu K G, Caner Özler E, Erdoğan K, Güney A, Sülüner S, Topal T, Tavukçuoğlu A, Toprak V, Türkmenoğlu A G, Üstünkaya M C \&Yaşar T (2007). Inventory of Ancient quarry characteristics, production and state landscapes in Turkey: their of conservation. Quarry Scapes: Conservation of Ancient Stone Quarry Land scapes in the Eastern Mediterranean, 8-14.

Erener A \& Yakar M (2012). Monitoring Coastline Change Using Remote Sensing and GIS Technologies. Lecture Notes in Information Technology, 30, 310314

Faro (2015). FARO® Laser Scanner Focus3D X 330. Erişim adresi: https://downloads.faro.com/index.php/s/Pz65S7Q 3P6zTPQf?dir=undefined $\&$ openfile $=42079$

Özdoğan M V \& Deliormanlı A H (2018). Yersel Lazer Tarayıcı ile Yeraltı Galerisinde Meydana Gelen Deformasyonların Belirlenmesi. Dokuz Eylül Üniversitesi - Mühendislik Fakültesi Fen ve Mühendislik Dergisi, 20(59), 663-675.

Özdoğan M V (2015). Madencilik Faaliyetleri Sonucu Oluşan Yüzey Hareketlerinin Yeni Teknolojiler İle Belirlenmesi. Dokuz Eylül Üniversitesi Fen Bilimleri Enstitüsü, Doktora Tezi, 183s, İzmir.

Özgüç T \& Akok M (1956). Ağzıkara Han. Ankara Üniversitesi Akademik Arşiv Sistemi. Yıllık Araştırmalar Dergisi (yayınlanmıyor), 1, 93-95.

Petrie G \& Toth C (2009). Terrestrial Laser Scanners. Topographic Laser Ranging and Scanning.

T.C. Kültür ve Turizm Bakanlığı. (t.y.). Selçuklu Kervansarayları Denizli-Doğubayazıt Güzergâhı. Erişim adresi https://kvmgm.ktb.gov.tr/TR44413/selcuklu-kervansaraylari-denizlidogubayazit-guzergahi.html

Tavukçuoğlu A, Düzgüneş A, Caner-Saltik E N \& Demirci Ş (2005). Use of IR thermography for the assessment of surface-water drainage problems in a historical building, Ağzikarahan (Aksaray), Turkey. NDT E Int., 38(5), 402-410.

Tavukçuoğlu A (2001). Ortaçağ taş anıtlarında nem sorunları ve çözümleri, Doktora Tezi, ODTÜ, Ankara.

Ulvi A \& Yakar M (2014). Yersel Lazer Tarama Tekniği Kullanarak Kızkalesi'nin Nokta Bulutunun Elde 
Edilmesi ve Lazer Tarama Noktalarının Hassasiyet Araştırması. Harita Teknolojileri Elektronik Dergisi, 6(1), 25-36.

Vozikis G, Haring A, Vozikis E ve Kraus K (2004). Laser scanning: A new method for recording and documentation in archaeology. In Proceedings of FIG Working Week.

Yakar M, Yıldız F \& Yılmaz H M (2005). Tarihi Ve Kültürel Miraslarin Belgelenmesinde Jeodezi Fotogrametri Mühendislerinin Rolü. TMMOB Harita ve Kadastro Mühendisleri Odası, 10.

Yakar M, Yılmaz H M \& Mutluoğlu H M (2009). Hacim Hesaplamalarında Laser Tarama ve Yersel Fotogrametrinin Kullanılması, TMMOB Harita ve Kadastro Mühendisleri Odası 12. Türkiye Harita Bilimsel ve Teknik Kurultayı, Ankara

Yakar M, Yilmaz H M \& Mutluoglu O (2010). Comparative Evaluation of Excavation Volume by TLS and Total Topographic Station Based Methods. Lasers in Engineering 19 (5-6), 331-345

Yaman B \& Ertunç Ç (2019). XIII. Yüzyıl Anadolu Taçkapıları'nda kullanılan madalyon ve kabaralar. İstem, 17(33), 127-148.

Yenil Ü \& Akyazı N (2019). Sürdürülebilir turizm kapsamında kültürel iz koridoru değerlendirmesi. Ömer Halisdemir Üniversitesi Mühendislik Bilimleri Dergisi, 8(2), 1179-1192.
Yetiş Ş \& Kaygısız N (2017). İpek Yolu Turizm Projesi kapsaminda Kapadokya'da yer alan kervansarayların turizme kazandırılması. Journal of Social and Humanities Sciences Research, 4(11), 522-527.

Yilmaz H M \& Yakar M (2008). Computing of Volume of Excavation Areas by Digital Close Range Photogrammetry. Arabian Journal for Science and Engineering 33 (1A), 63-79.

Yllmaz H M, Yakar M, Mutluoglu 0, Kavurmaci M M \& Yurt $\mathrm{K}$ (2012). Monitoring of soil erosion in Cappadocia region (SelimeAksaray-Turkey). Environ Earth Sci, $66,75-81$.

(c) Author(s) 2021.

This work is distributed under https://creativecommons.org/licenses/by-sa/4.0/ 